\title{
An amateur runner with hip pain and antalgic gait
}

\author{
Henry James Jonathon Hughes medical student ${ }^{1}$, Stefan Kluzek specialist registrar, sports and \\ exercise medicine ${ }^{2}$
}

${ }^{1}$ Oxford University Medical School, University of Oxford, Oxford, UK; ${ }^{2}$ Arthritis Research UK Centre for Sport, Exercise and Osteoarthritis, University of Oxford, Oxford, UK

A 52 year old amateur runner who had increased his running distance over a short period of time presented to clinic with a 17 week history of hip pain associated with antalgic gait. He had no other symptoms or medical history of note and was not taking any drugs. His blood tests showed low testosterone levels only, and his DEXA (dual energy x ray absorptiometry) scan was normal. Pelvic radiography was performed (fig 1); what is the diagnosis?

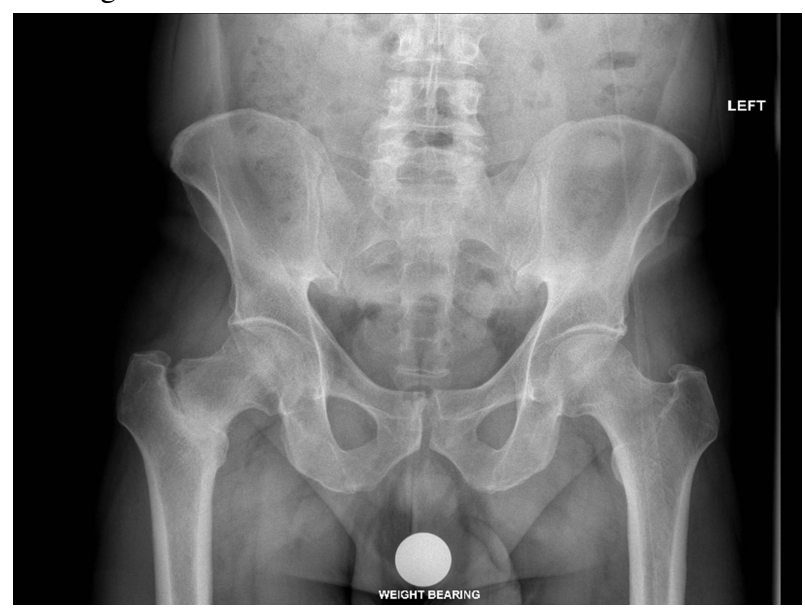

\section{Answer}

A tension side completed stress fracture of the right femoral neck.

\section{Discussion}

This is a classic presentation of a stress fracture: sudden onset of exercise related pain in an otherwise fit and well middle aged person who has recently increased his or her level of athletic activity. A decrease in bone mineral density is not necessary for stress fractures to occur. In addition to plain radiography, magnetic resonance imaging was performed to rule out infection or metastatic disease. The fracture was fixed with a sliding hip screw within 24 hours of presentation. Tension side fractures (superior aspect of the femoral neck) often need fixing because non-operative treatment has a high risk of failure and completion, whereas compression side fractures (inferior aspect of the femoral neck) usually heal with offloading. ${ }^{1}$

Stress fractures of the femoral neck are most commonly seen in military personnel and athletes with a high or suddenly increasing training load. ${ }^{1}$ Other risk factors include abnormal biomechanics, metabolic bone disease, metastatic deposits, and infection. ${ }^{2}$ It can be difficult to identify stress fractures of the hip because hip pain occurs at all ages and has several causes. ${ }^{3}$ A thorough medical and exercise history, followed by appropriate radiological investigation (plain radiography and magnetic resonance imaging), enables early diagnosis and implementation of appropriate management, thereby preventing complications. When treating stress fractures, underlying risk factors must be dealt with and lengthy offloading may be needed. Continued activity or premature return to loading exercise can result in completion of the stress fracture and later complications, such as avascular necrosis and early osteoarthritis. ${ }^{4}$

Competing interests: We have read and understood BMJ policy on declaration of interests and declare the following interests: none.

Provenance and peer review: Commissioned; not externally peer reviewed.

Patient consent obtained.

1 Polacek M, Småbrekke A. Displaced stress fracture of the femoral neck in young active adults. BMJ Case Rep 2010;2010:bcr0220102749. doi:10.1136/bcr.02.2010.2749 pmid: 22778106.

2 Behrens SB, Deren ME, Matson A, Fadale PD, Monchik KO. Stress fractures of the pelvis and legs in athletes: a review. Sports Health 2013;5:165-74. doi:10.1177/ 1941738112467423 pmid:24427386.

3 Gurney B, Boissonnault WG, Andrews R. Differential diagnosis of a femoral neck/head stress fracture. J Orthop Sports Phys Ther 2006;36:80-8. doi:10.2519/jospt.2006.36.2. 80 pmid: 16494075 .

4 Clough TM. Femoral neck stress fracture: the importance of clinical suspicion and early review. Br J Sports Med 2002;36:308-9. doi:10.1136/bjsm.36.4.308 pmid:12145125. 
Published by the BMJ Publishing Group Limited. For permission to use (where not already granted under a licence) please go to http://group.bmj.com/group/rights-licensing/

permissions 